\title{
A Study to Re-Design the Lay Out for Tertiary Level Health Care Mortuary
}

\author{
Vishva Deepak Bijawat ${ }^{1}$, Ankit Kumawat ${ }^{2}$, Vipin Gupta ${ }^{3}$ \\ ${ }^{1}$ Assistant Professor, Forensic Medicine, Medical College, Barmer, ${ }^{2}$ Resident in Physiology, J.L.N. Medical \\ College, Ajmer, ${ }^{3}$ Resident in Forensic Medicine, J.L.N. Medical College, Ajmer
}

\begin{abstract}
Autopsy, post-mortem examination or necropsy is the synonyms used for the examination of the dead body after death to collect all the necessary medicolegal evidences. The post-mortem examination is usually conducted in place which is called mortuary. The mortuary conditions in India are very bad in terms of infrastructure and facilities so they are not suitable to carry out scientific examination which results into post-mortem artefacts. Lack of instruments, facilities like electricity, water and antiseptic agents poses health hazards to mortuary attendant and doctors' working in mortuary. This paper is aimed at describing the required facilities in a scientifically designed mortuary along with modification in building designs of a district hospital mortuary which is going to become a mortuary of new medical college to serve the purpose of post-mortem examination along with teaching of doctors and nurses.
\end{abstract}

Keywords: Autopsy complex, mortuary lay out, requirements in mortuary, teaching mortuary.

\section{Introduction}

With this modernization era and increased craving of society to deliver speedy and prompt services, much neglected part in healthcare system brings attention of mankind to modernise the infrastructure and staffing of mortuary to give a human touch on handling and disposal of dead bodies for their legal proceedings. The proper and decent modern facilities in mortuary complex will dispel the atmosphere of dislike, fear and hatred associated with mortuary complex in general individual of this country and this will allow the reluctant visitor to visit the mortuary.

In India most of places including secondary and tertiary(medical college) care level mortuaries have

\footnotetext{
Corresponding Author:

Dr. Vishva Deepak Bijawat

Assistant Professor, Forensic Medicine, Medical

College, Barmer

e-mail:drvsvdpk@gmail.com
}

primitive facilities for body preservation as well as for autopsy examination, Even some of them deprived of basic necessity like electricity and water supply, Which needs urgent attention and redressal. The concept of a modern mortuary in a hospital, regards the mortuary as a culturally sensitive area in terms of public relation of the hospital ${ }^{1}$.

When a patient dies during the course of treatment or receives as brought dead to institution the post-mortem care starts in form of various procedures like washing of body, plugging of body orifices with cotton plug and covering in white cloth which imparts a Respect to Dead body as well as retards the decay of body. When body is required to be preserved for some time and then is dissected to find out the cause of death. This is called an autopsy or post-mortem examination in laymen's language. Post mortem examination is conducted to find out the cause of death may be for legal or scientific requirement depending on the circumstances leading to the death. The area where such procedure is carried out is called a Mortuary (Or Post-Mortem/Autopsy Room). On certain occasions, the body is also required to be preserved, till disposal arrangement is made either by the relative of the patients or the hospital authority 


\section{Role of an ideal mortuary complex:}

The various services provide includes ${ }^{2}$ :

- Documentation of incoming and outgoing bodies from Hospital to mortuary complex and their disposal and for identification of the body.

- PostMortem examination of the dead body to find out cause of death by forensic autopsies and pathological autopsies as well.

- The demonstration of Post Mortem findings for teaching purposes to undergraduates as well as postgraduates.

- To provide space for forensic evidence collection and storage until they are suitable for transport to FSL or Pathological Laboratories.

- To provide space for Family/police viewing and facilities for other specialised procedures like mobile Radiography, Photography and video recording etc.

\section{General guidelines for mortuary designs}

Every mortuary should have following minimum facilities $^{3}$ :

- Suitable arrangements for receiving the dead bodies from the hospital or outside, with separate arrangements for keeping decomposed and infectious bodies (known HIV/hepatitis death cases $)^{4}$ etc.

- Requisite space for post-mortem examination as well as to accommodate learning student, nurses or investigation officer.

- Other basic essential amenities like office,reception, toilets, Cold room, changing room, waiting room etc

- There should be fresh air and natural light to be available in each room of the mortuary with cleanliness \& hygiene.

- The mortuary complex must be located at a short distance from the hospital preferably away from the general traffic routes used by the public. It must have a separate entrance for visitors and dead bodies.

- There should be a direct link between the hospital and the mortuary to Facilitate easy delivery of the dead bodies for autopsy from the wards. It should have adequate parking space.

MCI guideline of Mortuary complex for 100 MBBS students intake per year: Autopsy Block-there shall be an Autopsy room (approx.400 sq. mt. area) with facilities for cold storage, for cadavers, ante-rooms, washing facilities, with an accommodation capacity of 20-25 students, waiting hall, office etc. The location of mortuary/autopsy block should be either in the hospital or adjacent to the hospital in a separate structure and may be shared with the department of Pathology 5 .

Staffing: The requirement of staff in the mortuary differs from place to place and depends on the type and quantum of work undertaken, the type of institute whether teaching or a Non-teaching hospital. The SubCommittee Report (Bureau of Police Research and Development of 1975) laid down the staffing pattern and this has been accepted in principle by the government.

I. For initial 100 autopsies per year: (i) SpecialistsTwo (ii) Post mortem technician-One.(iii) Post mortem Assistant- One.(iv) Clerk/Steno-One. (v) Chowkidar- One.(vi) Peon- One (vii) Sweeper/ Morgue attendants-4 (Three sweepers for shift duty round the clock and one as a reliever $)^{6}$.

II. For every additional 100 autopsies per year, following additional staff is required: (i) Specialist- One. (ii) Post mortem assistant - One. (iii) Technician- One (for teaching institutions). (iv) Assistant - (300-500 autopsies/yr)-One, $(>500$ autopsies/yr)Two.

In addition these staff mortuary should require (I) Photographer - One. (II) Dark room attendant- One (on big centres, personnel for photographic work)

Equipments: The equipments required in mortuary vary widely. Only those equipments that are of certain significance related to the mortuary complex are listed as under: (as per the recommendation of Survey Committee Report on Medico-legal Practices in India, 1964)

\section{(i) Basin E. I 12"-2}

(ii) Weighing machines 3 No. For weighing bodies, organs and foetus with top loading tray up to 500 gram and up to $5 \mathrm{~kg}$.

a. Platform scale for weighing the whole body

$-1$

b. Balance to weight $100 \mathrm{gms}$ to $10 \mathrm{~kg} \quad-\quad 1$

c. Balance to weigh 0.2 gms to $10 \mathrm{gms} \quad-1$

(iii) Cutting instruments-stainless steel:

a. Skull cutter (electrical) - 1 
b. Organ knife 10' blade, solid forged - 1

c. Organ knife 6" blade, solid forged - 1

d Caltin solid forged -

e Cartilage knife 5-1/2" blade solid forged 2

f Rib cutter

g Cartilage knife 4" blade/solid forged - 2

h Brain knife 10" blade, solid forged - 1

i Resection knife 3" blade, solid forged - 2

j Scalpels, BP Handle with blades - 1 Set

$\mathrm{k}$ Bistoury, probe pointed solid forged - 1

(iv) Scissors (stainless steel)

a. Scissors; blunt sharp 8" - 1

b. Scissors; blunt/sharp 6" - 1

c. Scissors; dissecting 5" with one probe point for coronary artery - 1

d Scissors; bowel, Bernard 11" -

(v) Forceps (stainless steel)

a. Bone cutting forceps 10" straight - 1

b. Bone cutting forceps 10" angled - 1

c. Rib-shears 9-1/2" - 1

d Dissecting forceps 6" $\quad-1$

e Dissecting forceps 8" - 1

f Dissecting forceps 10" - 1

g Toothed and un-toothed forceps - 6 each

(vi) Post-mortem Scissors:

a. Saw, Bernard 11" stainless steel Blade - 1

b. Saw, Bernard 9" stainless steel Blade — $\quad 1$

(vii) Straight and curved Enterotome, viscrotome - 1 each

\section{(viii) Miscellaneous:}

a. Coronet stainless steel

b. Needles, post-mortem half curved $\&$ double curved 1 dozen

c. Probes silver with eye 10"

d. Chisel, straight $3 / 4$ " blade e. Chisel, spine with locating point (stainless steel)

f. Gouge, 3/4" blade, stainless steel

g. Hammer with wrench stainless steel

h. Measures 12" stainless steel -

i. Mallet, boxwood with metal bands

j. Small table $20 " \times 24 " \times 12$ " for dissection of organs

k. Measuring jug (one litre) $\quad$ - $\quad 1$

1. Metal/steel scale - $\quad 2$

m. Magnifying glass - 3

n. Instrument trolley -

o. Cabinet $1-1$

p. Wooden boards - $\quad 3$

q. Rubber gloves - Adequate quantity

r. Aprons - Adequate quantity

This list covers almost the entire range of equipments for pos-mortem examination. However the following additions are also recommended by some of the authorities:

(viii) Suction Pump \& Aspirators - 1 each

(ix) Body Scale

$-1$

(x) Repairing materials like: Thread white, cotton wool (absorbent), wool waste, a variety of discarded clothes, malleable wire, Polythene bags, Gloves, Masks, and Aprons etc.

(xi) Plastic Bins: For fixing large specimens.

Chemical and Reagents: There should be provisions for following chemical articles.

(i) Bleaching powder for cleaning mortuary table floors, etc.

(ii) $2 \%$ Glutaraldehyde for cleaning instruments.

(iii) Formative for sending specimens needing his to pathology.

(iv) Rectified and Methylated spirit as preservative

2 (v) Thymol crystals 
(vi) Common salt

(vii) Sodium fluoride

(viii) Potassium oxalate

(ix) EDTA vials and tubes

(x) Sterilized glass tubes (plain).

(xi) Sterilized glass tubes with swabs

(xii) Liquid paraffin

(xiii) Sealing wax etc.

(xiv) Big size envelope, plain papers etc.

Universal Precaution: Eye protection (Goggles and face sheilds), Plastic Gowns, Personal protective equipment (PPE) \& Puncture resistant hand protection (plastic or steel gloves)-prevent blood borne transmission ${ }^{7}$.

\section{Material and Method}

A yearlong data from April 2017 to March 2018 collected from morgue register of District hospital, Barmer which showed total 268 dead bodies arrived at morgue among which 7 bodies are highly infectious (hepatitis -2, HIV-Aids-1,MDR-TB-1 and decomposed bodies 3).there is tendency of faster disposal of dead bodies to relatives on receiving the requisition of nonpostmortem from I.O. The usual average stay of dead body in mortuary remains around 6 hours particularly due to frequent power cuts and interrupted power supply. There were nine unidentified dead bodies disposed from mortuary fairly within 48-72 hrs. There was maximum intake of four dead bodies at a time reported with maximum two dead bodies retained overnight in the mortuary. The space around the fixed cemented mortuary table found inadequate to accommodate $20-25$ persons.

\section{Situation of Mortuary Complex:}

\begin{tabular}{|l|c|l|}
\hline Mortuary Complex & M & Visitors \\
& $\mathrm{A}$ & \\
$\mathrm{I}$ & \\
$\mathrm{N}$ & \\
$\mathrm{R}$ & Hospital Building \\
& $\mathrm{O}$ & \\
$\mathrm{A}$ & \\
& $\mathrm{D}$ & \\
\hline
\end{tabular}

\section{Proposed Extension of Mortuary Complex:}

\begin{tabular}{|c|c|c|c|}
\hline \multirow{2}{*}{$\begin{array}{c}\text { Open space } \\
\mathrm{Y}\end{array}$} & Doctor room & Toilets & \\
\cline { 3 - 3 } & & Post Mortem room & Open Space \\
Verandah & \multirow{2}{*}{ Entrance } & Body store \\
& & Store room \\
\hline
\end{tabular}

$\mathrm{X}$ : Proposed post mortem viewing gallery, Y: Proposed sample handling room etc.

\section{Conclusion}

As usual in the secondary care level hospital the condition of mortuary is worse since basic facilities like regular electric supply and water for cleaning dead bodies is not available. Due to lack of facilities there are chances of producing post mortem artefacts and missing out valuable findings. Provisions of mortuary facilities and services in a tertiary care hospital have an important bearing in terms of public relation of the hospital. To convert this mortuary into a teaching mortuary a post-mortem viewing gallery should be incorporated to accommodate the 20-25 students and a specimen handling room required as extension.
Ethical Clearance: Taken from institutional Ethics committee of new teaching (District) hospital, Barmer

\section{Source of Funding: Self}

\section{Conflict of Interest: Nil}

\section{References}

1. Brysiewicz $P$. The lived experience of working in a mortuary. Accid Emerg Nurs. 2007 Apr;15(2):8893.

2. Support services. C-4 Morgue \& autopsy, Section2Clinical Services, Partnershipsbc British Columbia. Resource (internet). Assessed 13.11.2019 
available from http://www.partnershipsbc.ca/pdf/ procurement

3. Smith GS, Dick A, Sissons HH. Mortuary designs and hazards. J ClinPathol. 1961 Mar;14(2):103-8.

4. Llewelyn-Davies, Richard, Macaulay, Hugh Montagu Cameron \& World Health Organization. (1966)!? Hospital planning and administration/R. Llewelyn-Davies, H. M. C. Macaulay. World Health Organization. https://apps.who.int/iris/ handle/10665/41781
5. Minimum standard requirements for the Medical College for 100 admissions annuallyregulations, 1999(internet)assessed on 13-11-2019.Available from https://www.mciindia.org/CMS/wpcontent/uploads/2017/10/Minimum-StandardRequirements-for-100-Admissions.pdf

6. The Committee on Plan Projects. Report on General Hospitals, 1964.

7. Odega, Kevin.Mortuary services set-up 'a step wise guideline and approach'. 2018. 10.13140/ RG.2.2.31302.78408. 